\title{
Etiology and Risk Factors Associated With Infertility
}

\author{
Azam Moridi ${ }^{\circledR}{ }^{\circledR}$, Nasibeh Roozbeh ${ }^{1}$, Halimeh Yaghoobi ${ }^{2}$, Shirin Soltani ${ }^{1}$, Sareh Dashti ${ }^{3}$, Nasim \\ Shahrahmani ${ }^{4}$, Mojdeh Banaei ${ }^{* *}$
}

\begin{abstract}
Objectives: Infertility is one of the important complications in gynecology and the aim of the present study was to investigate the etiology and risk factors associated with infertility in the southern region of Iran.

Materials and Methods: This cross-sectional study was conducted in infertility centers of Hormozgan University of Medical Science (HUMS). Totally, 250 infertile couples were included. The variables including socio-demographic characteristics, smoking, body mass index (BMI), and infertility status (e.g., type of fertility, duration, etc.) were assessed by a self-administered and validated questionnaire. Data analysis was carried out using SPSS version 22.0.

Results: The most common causes of male and female infertility were varicocele (49.4\%) and ovulation disorders (57.5\%), respectively. There was a significant association between female factor infertility and level of education, age of women, women's age at marriage, number of abortions, alcohol consumption, presence of an underlying disease, and BMI $(P<0.005)$. There was also a significant relationship between male factor infertility and men's job, addiction, smoking, and presence of an underlying disease $(P<0.005)$.

Conclusions: Considering various risk factors for infertility, an important step forward can be taken towards reducing the incidence of these risk factors by providing different education

classes during pre-marriage, pre-partum, pregnancy and postpartum periods so as to inform couples of controllable risk factors.

Keywords: Infertility, Male, Infertility, Female, Etiology, Risk factor, Iran
\end{abstract}

\section{Introduction}

Infertility is one of the most important complications in gynecology and is explained as the inability to achieve pregnancy after one year of unprotected intercourse (without the use of any contraceptive method) (1). The World Health Organization (WHO) has identified infertility as a global public health problem $(2,3)$.

Infertility is divided into primary and secondary categories based on the presence or absence of a previous pregnancy $(4,5)$. Both female and male factors can lead to infertility (6). Menstrual and ovulation disorders and uterine factors are among the most common causes of female infertility (7). Male infertility factors are known to reduce the production of sperms with normal morphology and progressive motility (8). Although infertility affects human fertility health status and there is a great deal of concern about identifying its risk factors, there are no comprehensive epidemiological studies about infertility risk factors (9).

The prevalence of infertility has increased significantly in recent years (10). The global prevalence of infertility is reported to be $10 \%-15 \%$ (11). The rates of male infertility in North America, Australia, and Europe were reported to be $4 \%-6 \%, 8 \%$, and $7.5 \%$, respectively (2). A metaanalysis of the causes of infertility among the patients who referred to several infertility clinics of Iran showed that $78.4 \%$ of the couples suffered from primary and $21.6 \%$ from secondary fertility problems. Totally, $34 \%$ of them had male factor, $43.5 \%$ had female factor and $17 \%$ had both male and female factors and $8.1 \%$ had no specified cause for their infertility (13). Finally, preconception care and counseling are recommended to all those who are planning a pregnancy to avoid failure which can make the couples prefer to remain childless or consider an agreement or non-spousal sperm options (7).

Therefore, because there is no exact information on infertility in the south of Iran, we decided to investigate the causes and risk factors of infertility in the south of Iran. Determining the causes and factors associated with infertility can offer better clues in the process of infertility treatment. Therefore, the aim of this study was to examine the etiology and risk factors associated with infertility in Bandar Abbas as the southernmost region of Iran.

\section{Materials and Methods}

This descriptive-analytic study was conducted in 2018 to 
investigate the etiology and risk factors associated with infertility in Bandar Abbas, Iran. The study population consisted of infertile couples referring to the infertility center of Omeleila hospital. This center was selected since it was the only center that provides infertility services in Bandar Abbas County. The sample size was calculated using the following formula and considering 95\% confidence level, sampling errors (d) of 0.04 , and prevalence rate $(\mathrm{p})$ of 0.15 according to previous studies (14). The calculated sample size was 244 couples, which was increased to 250 couples due to possible drop-outs.

$$
n=\frac{Z_{1-\frac{\alpha}{2}}^{2} \times p \times(1-p)}{d^{2}}
$$

The sampling was carried out systematically using a list of the patients registered in the center. The systematic sampling was carried out in a way that women whose medical records were archived in the center were randomly selected, and one person was selected as a sample from $\mathrm{K}$ individuals; $\mathrm{K}$ is the sampling interval and is determined by dividing the total number of qualified subjects by the number of individuals required in the sample. In this method, the first sample was selected randomly and the remaining ones were selected at $\mathrm{K}$ intervals. The inclusion criteria included all infertile women who referred to the center for the treatment of infertility, and the exclusion criteria included the unwillingness to participate in the study.

The data were collected by a researcher-made questionnairebasedon previousstudies. Thequestionnaires were completed using interviewing in a separate room after ensuring the confidentiality of the information and the way the information would be used in this research. A part of the questionnaire, which included specialized questions, was extracted from the medical documents of the subjects and entered in the questionnaire by the researcher. This questionnaire consisted of 40 questions in two parts; the first part included demographic information of couples including education level, occupation, level of income, place of residence (urban and rural), living close to the refinery or industrial towns, body mass index (BMI), presence of underlying diseases, smoking, alcohol consumption, and so on. The fertility data of the couples were also recorded in the second part. The infertility data included information on the type (primary, secondary) and duration of infertility, number of previous births and abortions, history of abnormal infant births, investigation of male factors of infertility, its causes, and the results of semen analysis retrieved from couples' medical records, and investigation of female factors of infertility and its causes. Moreover, the content validity of the researchermade questionnaire was assessed.

Firstly, the questionnaire was prepared based on the libraries and online sources including articles and researches. Then, the validity of the tool was determined by 15 faculty members of Hormozgan University of Medical Sciences. The viewpoints and opinions of the experts were addressed in the revised questionnaire. The face validity of the questionnaire was also evaluated both qualitatively and quantitatively through the impact score, and the results showed that all questions were appropriate in terms of appearance. The content validity of this questionnaire was evaluated both qualitatively and quantitatively by calculating content validity index (CVI) and content validity ratio (CVR). Finally, the CVR and CVI values of the questionnaire were obtained as 0.94 and 0.92 , respectively, indicating good content validity. Considering the good face and content validity of this tool, no question was omitted. A test-retest method was also used to assess the reliability of the instrument.

The questionnaire was completed in two stages, with 2 -week intervals between, by 10 infertile couples referring to the infertility center of Omeleyla hospital who met the inclusion criteria. It should be noted that these subjects were not included in the main research. The reliability of the responses given in two stages was confirmed by a reliability coefficient of 0.84 .

This research was carried out after obtaining the approval from the Ethics Committee of Hormozgan University of Medical Sciences (HUMS.REC.1395.104) as well as permission from Hormozgan University of Medical Sciences. The researcher then introduced himself to the research centers by submitting a written selfintroduction letter and obtained written consent forms from the subjects. The research method, objectives, and the period of study were explained to the subjects. They were then enrolled in the study and were asked to reply to questions honestly.

\section{Statistical Analysis}

The data were analyzed using SPSS (Statistical Package for the Social Sciences) software version 21.0. The mean and standard deviation (SD) were used to determine and describe the quantitative variables. In addition, a logistic regression model was used to determine the risk factor of infertility. A $P$ value of less than 0.05 was considered statistically significant.

\section{Results}

The sociodemographic characteristics of the subjects and their spouses are presented in Table 1. The mean ages of infertile women and their spouses were $31.2 \pm 5.94$ and $35.7 \pm 6.70$ years, respectively. The average ages at marriage for women and their spouses were 23 and 27.6 years, respectively. It was found that $2.99 \%(n=2)$ of the subjects lived near the refinery or industrial towns and about $12.8 \%(n=32)$ of the husbands of the subjects were employed in refineries and industrial towns. On average, infertile men worked in the refinery and industrial towns for 11.6 hours per day and 5.7 times a week. In addition, $8 \%(n=20)$ of the subjects had a history of smoking 8.2 
Table 1. Frequency Distribution of Subjects Based on Demographic and Fertility Characteristics

\begin{tabular}{|c|c|c|}
\hline & Sub-group & No. (\%) \\
\hline \multicolumn{3}{|c|}{ Demographic Variables } \\
\hline \multirow{3}{*}{ Wife's level of education } & Under diploma & $71(28.4)$ \\
\hline & Diploma & $76(30.4)$ \\
\hline & Above diploma & $103(41)$ \\
\hline \multirow{3}{*}{ Husband's level of education } & Under diploma & $72(28.8)$ \\
\hline & Diploma & $85(34)$ \\
\hline & Above diploma & $93(37.2)$ \\
\hline \multirow{2}{*}{ Monthly income (Tomans) } & $<1$ million & $29(11.6)$ \\
\hline & $\geq 1$ million & $221(88.4)$ \\
\hline \multirow{2}{*}{ Place of residence } & City & $29(11.6)$ \\
\hline & Village & $36(14.4)$ \\
\hline \multirow{2}{*}{ Residence status } & Owner & $96(38.4)$ \\
\hline & Tenant & $154(61.6)$ \\
\hline \multicolumn{3}{|c|}{ Fertility Variables } \\
\hline \multirow{2}{*}{ Type of infertility detected } & Primary & $187(74.8)$ \\
\hline & Secondary & $63(25.2)$ \\
\hline \multirow{2}{*}{ Childbirth history } & Yes & $41(16.4)$ \\
\hline & No & $209(83.6)$ \\
\hline \multirow{2}{*}{ Type of previous delivery } & Normal & $9(22)$ \\
\hline & Cesarean section & $32(78)$ \\
\hline \multirow{2}{*}{ History of abortion } & Yes & $74(29.6)$ \\
\hline & No & $176(70.4)$ \\
\hline \multirow{3}{*}{ Number of abortions } & Once & $50(67.6)$ \\
\hline & Twice & $17(23)$ \\
\hline & 3 times and more & $7(9.5)$ \\
\hline \multirow{4}{*}{$\begin{array}{l}\text { Female BMI status during } \\
\text { pre-pregnancy }\end{array}$} & Underweight & $10(4)$ \\
\hline & Normal & $142(56.8)$ \\
\hline & Overweight & $75(30)$ \\
\hline & Obese & $23(9.2)$ \\
\hline \multirow{2}{*}{$\begin{array}{l}\text { History of underlying } \\
\text { diseases in couples }\end{array}$} & Yes & $72(28.8)$ \\
\hline & No & $178(71.2)$ \\
\hline \multirow{2}{*}{$\begin{array}{l}\text { History of having an } \\
\text { abnormal child }\end{array}$} & Yes & $4(1.6)$ \\
\hline & No & $246(98.4)$ \\
\hline \multirow{2}{*}{$\begin{array}{l}\text { Wife's relationship with her } \\
\text { husband }\end{array}$} & Yes & $89(35.6)$ \\
\hline & No & $161(64.4)$ \\
\hline \multirow{2}{*}{ Woman's job } & Housewife & $201(80.4)$ \\
\hline & Employed & $49(19.6)$ \\
\hline \multirow{2}{*}{ Husband's job } & Unemployed & $6(2.4)$ \\
\hline & Employed & $244(97.6)$ \\
\hline \multirow{2}{*}{$\begin{array}{l}\text { History of alcohol } \\
\text { consumption }\end{array}$} & Yes & $6(2.4)$ \\
\hline & No & $244(97.6)$ \\
\hline \multirow{2}{*}{ History of smoking } & Yes & $20(8)$ \\
\hline & No & $230(92)$ \\
\hline \multirow{2}{*}{ History of addiction } & Yes & $17(6.8)$ \\
\hline & No & $233(93.2)$ \\
\hline
\end{tabular}

Table 1. Continued

\begin{tabular}{|c|c|c|}
\hline \multicolumn{3}{|c|}{ Midwifery Variables } \\
\hline \multirow{6}{*}{$\begin{array}{l}\text { Duration of primary } \\
\text { infertility }\end{array}$} & 1 year & $16(8.6)$ \\
\hline & 2 years & $24(12.8)$ \\
\hline & 3 years & $20(10.7)$ \\
\hline & $3-5$ years & $31(16.6)$ \\
\hline & $5-10$ years & $52(27.8)$ \\
\hline & More than 10 years & $44(23.5)$ \\
\hline \multirow{6}{*}{$\begin{array}{l}\text { Duration of secondary } \\
\text { infertility }\end{array}$} & 1 year & $4(6.3)$ \\
\hline & 2 years & $17(27)$ \\
\hline & 3 years & $5(7.9)$ \\
\hline & $3-5$ years & $13(20.6)$ \\
\hline & $5-10$ years & $17(27)$ \\
\hline & $>10$ years & $7(11.1)$ \\
\hline \multirow{3}{*}{$\begin{array}{l}\text { History of any underlying } \\
\text { disease }\end{array}$} & Wife & $51(70.8)$ \\
\hline & Husband & $16(22.2)$ \\
\hline & Both & $5(9.6)$ \\
\hline \multirow{3}{*}{$\begin{array}{l}\text { Age of the first menstrual } \\
\text { period }\end{array}$} & 1-9 years old (early) & $3(2.1)$ \\
\hline & $9-13$ years old & $176(70.4)$ \\
\hline & $\begin{array}{l}\text { 13-16 years old } \\
\text { (late) }\end{array}$ & $71(28.4)$ \\
\hline
\end{tabular}

cigarettes per day for an average duration of 8 years. A total of $17(6.8 \%)$ subjects also mentioned the history of addiction, including opium and hookah, which was referred to as the most common drug used with an average frequency of 1.9 times a day.

The causes of infertility were divided into three categories: male, female, and both, with the frequency of $22.8 \%, 51.2 \%$, and $26 \%$, respectively. Figure 1 shows the distribution of male-female causes of infertility in percentage. The most common cause of male infertility was vascular disorders including varicocele (49.4\%).

Sexual factors referred to as sexual dysfunction of each couple included vaginismus, the way and time of sexual intercourse, any sexual problem that prevents pregnancy, and other causes included narcotic use, systemic disease, drug use, and so on. According to the results of semen analysis, the most commonly diagnosed cases included azoospermia (56.4\%) followed by oligozoospermia (24.5\%), teratozoospermia (9.6\%), asthenozoospermia $(4.8 \%)$, aspermia $(2.9 \%)$, and oligoasthenoteratospermia (1.8\%), respectively (Figure 1 ).

Figure 2 shows the distribution of female infertility causes in percentage. The most common female infertility cause was ovulation disorders $(57.5 \%)$, which was mainly due to polycystic ovary syndrome (PCOS) (66.2\%). Other causes of female infertility included menstrual disorders, autoimmune disorders, galactosemia, smoking and drug addiction, chemotherapy and radiation therapy, systemic diseases, and so on (16.2\%), thyroid disorders (5.2\%), hyperprolactinemia (5.1\%), hyperprolactinemia and 


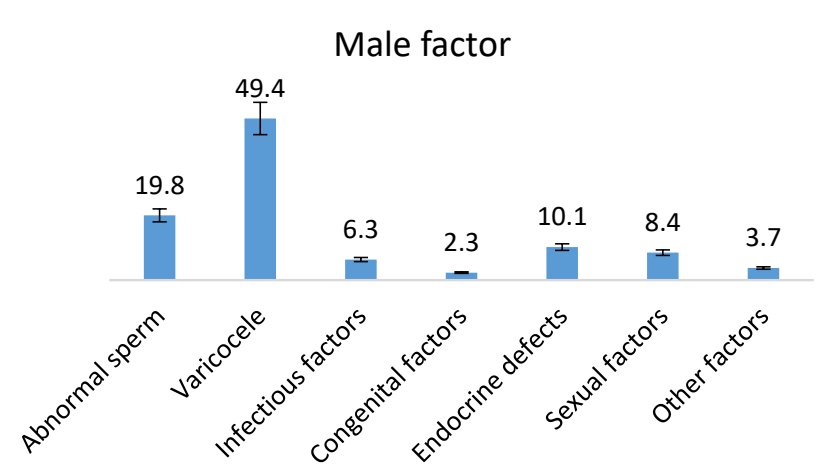

Figure 1. Distribution of the Causes of Male Infertility.

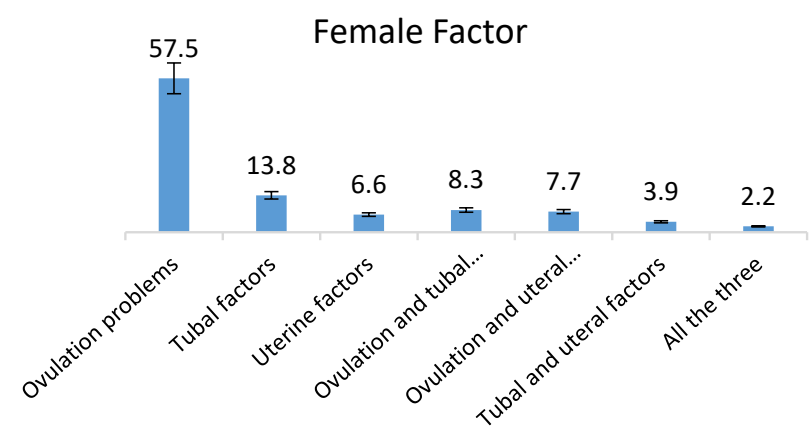

Figure 2. The Distribution of the Causes of Female Infertility.

PCOS (4.4\%), thyroid disorders and PCOS (2.2\%), and hypothalamic disorders $(0.7 \%)$. The most common cause of female tubal-factor infertility was tubal spasm (55.8\%) and the most common cause of uterine factor infertility was intrauterine adhesions (31.7\%).

In the present study, logistic regression was used to determine the causes of female infertility (Table 2).

The results showed that the odds of having female infertility for each one-year increase in education were 2.35 times higher compared to the other cases (95\% CI $=1.03-5.36 \%)$. The odds of infertility increased by 0.98 for each one-year increase in the individuals' age (95\% CI $=1.3-3.12 \%)$. The odds of female infertility increased by 1.41 for each one-year increase in the individuals' age at the time of marriage, which was statistically significant (95\% CI $=0.89-0.99)$. The odds of female infertility factor also increased 0.94 times for an increase in the number of abortions (95\% CI $=0.30-0.94)$. The odds of female infertility in women with a history of alcohol consumption were 0.78 times higher compared to those who did not mention the history of alcohol use (95\% CI $=1.72-4.97$ ). Furthermore, in women with a history of underlying disease including thyroid disorders, diabetes, and hypertension, the odds of infertility were 0.54 times higher compared to those with no underlying disease history (95\% CI $=0.30-95 \%)$.

Finally, the odds for infertility were 1.69 times higher per unit increase in BMI (95\% CI $=0.20-0.96)$ in such a way that the odds of infertility in obese and overweight women were higher compared to normal weight and underweight women.

In this study, logistic regression was used to determine factors associated with male infertility (Table 3 ).

The results indicated that the odds of male infertility in employed men were 1.55 times higher than that of unemployed men (95\% CI $=0.43-0.84)$. Furthermore,

Table 2. Results of Logistic Regression Based on the Factors Related to Female Infertility

\begin{tabular}{|c|c|c|c|c|c|}
\hline \multirow{2}{*}{ Variables } & \multirow{2}{*}{ Standard Deviation } & \multirow{2}{*}{ OR } & \multirow{2}{*}{$P$ Value } & \multicolumn{2}{|c|}{ 95\% Cl for EXP (B) } \\
\hline & & & & Lower Level & Upper Level \\
\hline Woman's age & 0.02 & 0.98 & 0.012 & 1.03 & 3.12 \\
\hline Woman's job & 0.34 & 1.14 & 0.701 & 0.57 & 2.25 \\
\hline Women's education & 0.41 & 2.35 & 0.040 & 1.03 & 5.36 \\
\hline Age at menarche & 0.32 & 0.58 & 0.089 & 0.31 & 1.08 \\
\hline Age at marriage & 0.64 & 1.41 & 0.041 & 0.89 & 0.99 \\
\hline Family relationship & 0.31 & 0.60 & 0.102 & 0.32 & 1.10 \\
\hline Family income & 0.97 & 0.87 & 0.708 & 0.43 & 1.77 \\
\hline Place of residence & 0.42 & 0.82 & 0.660 & 0.35 & 1.92 \\
\hline Housing status & 0.31 & 1.67 & 0.596 & 0.24 & 11.24 \\
\hline Type of delivery & 0.88 & 0.62 & 0.601 & 0.11 & 3.58 \\
\hline Gravida & 0.27 & 1.11 & 0.115 & 0.79 & 1.98 \\
\hline Number of abortions & 0.47 & 0.94 & 0.004 & 0.30 & 0.94 \\
\hline History of previous molar pregnancy & 0.81 & 0.67 & 0.632 & 0.13 & 3.33 \\
\hline Desired number of children & 0.92 & 2.12 & 0.418 & 0.34 & 13.11 \\
\hline History of a previous abnormal child & 2.29 & 0.2 & 0.902 & 0.34 & 4.40 \\
\hline Addiction & 0.92 & 1.77 & 0.536 & 0.29 & 10.83 \\
\hline Smoking & 2.40 & 0.02 & 0.978 & 0.01 & 3.13 \\
\hline Alcohol consumption & 0.14 & 0.78 & 0.001 & 1.72 & 4.90 \\
\hline The presence of underlying disease & 0.29 & 0.54 & 0.035 & 0.30 & 0.95 \\
\hline BMI & 0.24 & 1.69 & 0.001 & 0.20 & 0.96 \\
\hline
\end{tabular}

$d f=1, P<0.05$. 
Table 3. Results of Logistic Regression Based on Factors Related to Male Infertility

\begin{tabular}{|c|c|c|c|c|c|}
\hline \multirow{2}{*}{ Variables } & \multirow{2}{*}{ Standard Deviation } & \multirow{2}{*}{ OR } & \multirow{2}{*}{$P$ Value } & \multicolumn{2}{|c|}{ 95\% Cl for EXP (B) } \\
\hline & & & & Lower Level & Upper Level \\
\hline Man's age & 0.01 & 0.99 & 0.862 & 0.96 & 1.03 \\
\hline Men's job & 1.10 & 1.55 & 0.033 & 0.43 & 0.84 \\
\hline Men's level of education & 0.21 & 0.15 & 0.089 & 0.01 & 1.33 \\
\hline Age at marriage & 0.02 & 1.02 & 0.238 & 0.98 & 1.07 \\
\hline Family relationship & 0.26 & 0.86 & 0.599 & 0.51 & 1.46 \\
\hline Family income & 0.36 & 0.87 & 0.708 & 0.43 & 1.67 \\
\hline Place of residence & 0.39 & 1.63 & 0.215 & 0.75 & 3.56 \\
\hline Housing status & 1.11 & 0.55 & 0.593 & 0.06 & 4.89 \\
\hline Desired number of children & 0.28 & 0.60 & 0.071 & 0.34 & 1.04 \\
\hline Abnormal birth history & 0.89 & 0.32 & 0.876 & 0.02 & 1.23 \\
\hline Addiction & 0.51 & 1.53 & 0.019 & 0.19 & 0.75 \\
\hline Smoking & 0.46 & 1.78 & 0.007 & 0.03 & 0.79 \\
\hline Alcohol consumption & 1.12 & 0.19 & 0.144 & 0.02 & 1.75 \\
\hline The presence of underlying disease & 1.16 & 6.33 & 0.048 & 0.07 & 0.93 \\
\hline BMI & 0.62 & 1.87 & 0.151 & 0.23 & 1.65 \\
\hline
\end{tabular}

$d f=1, P<0.05$.

the odds of infertility in men who had a history of underlying disease including thyroid disorders, diabetes, and hypertension were 6.33 times higher compared to men without a history of the underlying disease (95\% CI $=0.07-0.93)$. Finally, the odds of infertility in men with a history of addiction were 1.55 times higher compared to men without a history of addiction (95\% CI= 0-19-0.75\%), and the odds of infertility were $1.78 \%$ higher in case of smoking each single cigarette, which was statistically significant $(95 \% \mathrm{CI}=0.03-79 \%)$.

\section{Discussion}

Infertility is a prevalent disease that results in profound health and socio-economic impacts on both the person and the community (10). The present study was conducted to investigate the etiology and risk factors associated with infertility in the southernmost city of Iran, Bandar Abbas. In the present study, the female factor infertility accounted for the highest rate of infertility (51.2\%), which was consistent with the results of other studies conducted in Iran $(10,7)$. In contrast to our study, another study carried out at Royan Institute, Tehran, Iran, referred to the male factor as the primary cause of infertility (15). This discrepancy may be due to different study design, characteristics of the participants, and sample size. In most studies, the frequency of male and female factors, both of them, and other unknown cause were $20-40 \%, 30$ $35 \%, 35 \%$, and 5-15\%, respectively (10,7). Infertile couples usually report more than one reason for their infertility and there are fewer single causes (7).

The results of the present study showed that the most common cause of male infertility was vascular disorders including varicocele (49.4\%). According to the results of semen analysis, the most commonly diagnosed causes included azoospermia (56.4\%) and oligozoospermia (24.5\%). A previous study showed that varicocele was the most common cause of male infertility, which was consistent with the results of the present study (16). Varicocele increases testicular temperature and reflux of toxic metabolites to the left kidney and ultimately leads to infertility by reducing the sperm parameters (7). Moreover, another study showed that in infertile men with varicocele, a decrease in serum testosterone levels leads to testicular atrophy (narrowing of the testicle), followed by disturbance in Leydig cells $(16,17)$. Contrary to the findings of our study, another study in 2015 reported seminal disorders as the most common cause of male infertility (7).

The most common causes of female infertility included ovulation disorders (57.5\%), and the most common cause of non-ovulation disorders was PCOS (66.2\%). The results of a study in Iran in 2015 showed that the most common cause of female infertility was ovulation disorders (39.7\%), which is consistent with the results of the current study (10). PCOS is a hereditary condition, in which ovulation fails to occur in more than $90 \%$ of cases (18). In PCOS, levels of hormones including androgens and testosterone increase due to high levels of luteinizing hormone (LH) and low levels of the follicular-stimulating hormone (FSH), so follicles in these individuals are prevented from producing a mature egg. Furthermore, PCOS increases the risk of insulin resistance, along with type 2 diabetes, which is one of the causes of infertility (18).

The findings of the present research also showed that the odds of female infertility increased by 0.94 for each abortion $(P=0.004)$, this is consistent with the findings of the study by Cong et al (3). In another study, a history of induced abortion was associated with worse IVF outcomes, especially a history of more than 2 surgical abortions (19).

Based on this finding, we support women's access to contraceptives to improve their fertility. In the present study and another study, the women's age and their age at marriage are factors that affect infertility. The age at 
marriage was higher in infertile women than in fertile women (3). Contrary to the results of our study, another study showed that the age at marriage had no effect on infertility $(P=0.269)(10)$. Further, some studies have shown that ovulation disorders result in infertility in women who married late or who tend to delay their pregnancy (20). It has been reported that age is one of the main causes of female infertility (21). The woman's fertility is at its peak between the ages of 18 and 24 years, while fertility begins to decrease gradually at the age of 27 years, and then declines sharply around the age of 35 . In other words, ovarian reserves decrease with increasing age (18). Based on these findings, we support the right age for marriage.

Women's level of education was one of the factors affecting female infertility. Colleran et al reported that postponed marriage and delay in pregnancy may increase the risk of infertility in educated women (22).

The present study showed that the odds of female infertility factor in alcoholic women were 0.78 higher compared to those who did not mention the history of alcohol consumption. A study showed that alcoholic women experienced higher rates of menstrual dysfunction, abortion, ovulation disorders, and endometriosis, followed by infertility. Chronic alcohol consumption has been reported to result in premature menopause and alcohol overconsumption reduces FSH levels (23).

The presence of underlying diseases including thyroid disorders was one of the risk factors for infertility in the present study. The prevalence of PCOS or premature ovarian failure is higher in infertile women with endometriosis, and autoimmune thyroiditis compared to fertile women (24). In hypothyroidism, serum thyroxine levels decrease, while serum levels of the thyrotropin-releasing hormone, thyroid stimulating hormone (TSH), and prolactin increase and the resultant hyperprolactinemia leads to ovulation failure (18). On the other hand, in hyperthyroidism, serum TSH level decreases and serum levels of T4, T3 or both increase. The serum levels of sex hormone binding globulin (SHBG) and estradiol (E2) are increased in women with hyperthyroidism as compared to euthyroid women. This increase in serum estradiol levels may lead to an increase in SHBG level or an increase in the production of androgen E2 (including plasma levels of testosterone and androstenedione), an increase in the LH/ FSH ratio and ovulation failure (25). Moreover, another study also showed that the incidence of hypertension was $15 \%$ higher in women with tubal infertility than in other women. Estrogen and androgen are thought to reduce the risk of hypertension. Therefore, the risk of hypertension changes in women with any type of infertility due to changes in hormonal levels (26).

In the present study, for each unit increase in BMI in women, the odds of infertility increased by 1.69 folds in such way that the odds of infertility in obese and overweight women were higher compared to normal and lean weight women. Eniola et al (18) reported that ovulation disorders lead to infertility due to weight gain (BMI greater than 27). Another study revealed that the probability of obesity and overweight in infertile women was 4.8 and 3.8 times higher compared to fertile women, respectively (27). Furthermore, Cong et al (3) showed a significant relationship between BMI $>30$ and female infertility factor. Estrogen is produced by fat cells and primary sex organs; therefore, high levels of fat or obesity leads to an increase in estrogen levels. The odds of getting pregnant and continuation of pregnancy are reduced due to hormonal balance. On the contrary, lower levels of fat lead to irregular menstrual cycles and menstrual cycles without ovulation due to inadequate estrogen production (28).

The results of our study showed that the odds of male factor infertility in employed men were1.55 times higher compared to unemployed men. In fact, over the past decades, there has been evidence of a decline in sperm quality following occupational exposure to some factors including organic solvents, pesticides, metals (lead and mercury), physical exposure to radiation and heat, occupational stress, and psychological factors (29). Another study showed that Exposure to pesticides was associated with a significantly higher risk of asthenozoospermia and necrozoospermia. Exposure to cement was found to be associated with a higher risk of oligozoospermia. There was no association between semen impairment and exposure to solvents, excess heat, or mechanical vibrations (30).

The present study revealed a significant relationship between male infertility factor and addiction and smoking $(P=0.019, P=0.007)$. Another study indicated that $60 \%$ of smokers were infertile (18). Smoking affects various parameters of semen and leads to a decrease in the concentration, motility, and antioxidants activity of sperm and thus affects the normal morphology of the sperm (31). Caserta et al (32) concluded that there was a significant relationship between cigarette smoking and oligospermia in men, progressive motility and decreased sperm concentration, however, no significant relationship was observed between cigarette smoking and sperm morphology. The result of a number of studies on male smokers showed that severe injuries to spermatogonia or chromosomal damages can be caused by smoking, which may prevent oocyte fertilization or impede the development of the embryo. This effect of smoking can lead to infertility and reduce fertility potential in an individual (33). Another study showed that tobacco use and addiction to other drugs resulted in reduced sperm morphology and progressive sperm motility but did not affect sperm count (34).

The present study showed that the underlying disease is a risk factor for male infertility. In a meta-analysis, Glazer et al (35) showed that infertile men had lower levels of testosterone and a higher level of anxiety and 
stress, leading to the release of more stress hormones and increase of the risk of cardiovascular diseases, diabetes, and death. Diabetes affects the fertility of the individual through the effects of the endocrine control on spermatogenesis or erectile dysfunction, leading to male sexual dysfunction and ultimately infertility. Additionally, diabetes is associated with a higher level of sperm DNA damage that may result in infertility (36).

Finally, based on the results, we propose ways to prevent infertility such as avoiding tobacco smoking and alcohol, as it damages sperm DNA, avoiding excessive heat to the testes, treatment of STDs, condom (latex male condoms and polyurethane vaginal sheath (female condom) use for safer sex, treatment of chronic diseases (e.g., diabetes), recommendation to lose weight, reducing occupational exposure and so on.

One of the limitations of the present study was the inability to measure the ovarian reserve. Another limitation was the lack of a fertile female group to make comparison in risk factors.

\section{Conclusions}

Overall, the causes of female infertility in the present study accounted for the highest infertility rate. Factors including woman's level of education, age, the age at marriage, number of abortions, alcohol consumption, underlying disease, and BMI were significantly correlated with female factor infertility. Besides, there was also a significant relationship between male factor infertility and men's occupation, addiction, smoking, and presence of underlying disease. Considering the various risk factors for infertility, conducting different education classes during pre-marriage, pre-pregnancy, pregnancy and postpartum periods to inform couples of controllable risk factors can be an important step towards reducing the incidence of these risk factors.

\section{Conflict of Interests}

Authors declare that they have no conflict of interests.

\section{Ethical Issues}

This study was approved by Hormozgan University of Medical Sciences (HUMS.REC.1395.104).

\section{Financial Support}

This study was financially supported by Mother and Child Welfare Research Center of Hormozgan University of Medical Sciences.

\section{Acknowledgments}

The authors wish to acknowledge Dr. Dashti for editing the manuscript. The researchers need to thank and appreciate the administrators and officials of the Hormozgan University of Medical Sciences as well as all the study subjects who provided us with the information required for conducting this study.

\section{References}

1. Rodriguez-Purata J, Polyzos NP. The endometrium during and after ovarian hyperstimulation and the role of segmentation of infertility treatment. Best Pract Res Clin Endocrinol Metab. 2018:33(1):61-75. doi: 10.1016/j. beem.2018.09.003

2. Agarwal A, Mulgund A, Hamada A, Chyatte MR. A unique view on male infertility around the globe. Reprod Biol Endocrinol. 2015;13(1):37. doi:10.1186/s12958-015-00321.

3. Cong J, Li P, Zheng L, Tan J. Prevalence and risk factors of infertility at a rural site of Northern China. PloS One. 2016;11(5):e0155563. doi:10.1371/journal.pone.0155563.

4. Al-Asadi JN, Hussein ZB. Depression among infertile women in Basrah, Iraq: Prevalence and risk factors. J Chinese Med Assoc. 2015;78(11):673-7.6. doi:10.1016/j. jcma.2015.07.009

5. Sethi P, Sharma A, Goyal LD, Kaur G. Prevalence of psychiatric morbidity in females amongst infertile couples-A hospital based report. J Clin Diagn Res. 2016;10(7):VC04. doi: 10.7860/JCDR/2016/19639.8090.

6. Olive K, Sekar K, Susila C. Level of anxiety among women with infertility problems, at Pondicherry city hospital, Puducherry: a descriptive study. IJCN. 2014;1(1):48-51.

7. Masoumi SZ, Parsa P, Darvish N, Mokhtari S, Yavangi M, Roshanaei G. An epidemiologic survey on the causes of infertility in patients referred to infertility center in Fatemieh Hospital in Hamadan. Iran J Reprod Med. 2015;13(8):513.

8. Shokoohi M, Shoorei H, Soltani M, Abtahi-Eivari SH, Salimnejad R, Moghimian M. Protective effects of the hydroalcoholic extract of Fumaria parviflora on testicular injury induced by torsion/detorsion in adult rats. Andrologia. 2018;16:e13047.doi/abs/10.1111/and.13047.

9. Meng Q, Ren A, Zhang L, et al. Incidence of infertility and risk factors of impaired fecundity among newly married couples in a Chinese population. Reprod Biomed Online. 2015;30(1):92-100. doi:10.1016/j.rbmo.2014.10.002.

10. Kazemijaliseh H, Tehrani FR, Behboudi-Gandevani S, Hosseinpanah F, Khalili D, Azizi F. The prevalence and causes of primary infertility in Iran: a population-based study. Glob J Health Sci. 2015;7(6):226.doi: 10.5539/gjhs. v7n6p226.

11. Curtis M. Inconceivable: how barriers to infertility treatment for low-income women amount to reproductive oppression. Georgetown Journal on Poverty Law \& Policy. 2017;25:323.

12. Moghadam AD, Delpisheh A, Sayehmiri K. The trend of infertility in Iran, an original review and meta-analysis. Nurs Pract Today. 2015:14;1(1):46-52.

13. Parsanezhad ME, Jahromi BN, Zare N, Keramati P, Khalili A, Parsa-Nezhad M. Epidemiology and etiology of infertility in Iran, systematic review and meta-analysis. Journal of Womens Health, Issues and Care. 2016:5;2013. doi:10.4172/2325-9795.1000121.

14. Morelli MA, Iuliano A, Schettini SC, et al. NMR metabolomics study of follicular fluid in women with cancer resorting to fertility preservation. J Assist Reprod Genet. 2018:1;35(11):2063-70. doi:10.1007/s10815-0181281-7.

15. Safarinejad MR. Infertility among couples in a population- 
based study in Iran: prevalence and associated risk factors. Int J Androl. 2008;31(3):303-14.

16. Dai RL, Hou Y, Li FB, Yue JM, Xi Q, Liu RZ. Varicocele and male infertility in Northeast China: Y chromosome microdeletion as an underlying cause. Genet Mol Res. 2015:14(2):6583-90. doi: 10.4238/2015.June.12.13.

17. Shokoohi M, Madarek EO, Khaki A, et al. Investigating the effects of onion juice on male fertility factors and pregnancy rate after testicular torsion/detorsion by intrauterine insemination method. Int J Womens Health Reprod Sci. 2018;6(4):499-505. doi:10.15296/ijwhr.2018.82.

18. Eniola OW, Adetola AA, Abayomi BT. A review of Female Infertility; important etiological factors and management. Journal of Microbiology and Biotechnology Research. 2017:31;2(3):379-85.

19. Wang Y, Sun Y, Di W, Kuang YP, Xu B. Association between induced abortion history and later in vitro fertilization outcomes. Int J Gynecol Obstet. 2018;141(3):321-6. doi:10.1002/ijgo.12481.

20. Behboudi-Gandevani S, Ziaei S, Khalajabadi-Farahani F, Jasper M. Iranian primigravid women's awareness of the risks associated with delayed childbearing. Eur J Contracept Reprod Health Care. 2013;18(6):460-7.

21. Amanvermez R, Tosun M. An update on ovarian aging and ovarian reserve tests. Int J Fertil Steril. 2016;9(4):411. doi: 10.22074/ijfs.2015.4591.

22. Colleran H, Jasienska G, Nenko I, Galbarczyk A, Mace R. Fertility decline and the changing dynamics of wealth, status and inequality. Proc R Soc B 2015:7;282(1806):20150287. doi: 10.1098/rspb.2015.0287.

23. Mendoza-López MD, Reyes-Martin KI, Gutiérrez-Gómez YY. Dietary intake and infertility: a review. FASEB J. 2015;29(1 suppl):590-12.

24. Sharique AA, Sharique M, Shah SW. Insight into Female Endocrine Infertility and its Relationship to Body Mass Index. Annals of Abbasi Shaheed Hospital \& Karachi Medical \& Dental College. 2016:1;21(4):214-220.

25. Weiss RV, Clapauch R. Female infertility of endocrine origin. Arq Bras Endocrinol Metabol. 2014;58(2):144-52.

26. Tobias DK, Gaskins AJ, Missmer SA, et al. History of infertility and risk of type 2 diabetes mellitus: a prospective cohort study. Diabetologia. 2015;58(4):707-15. doi: 10.1007/s00125-015-3493-z.

27. Broughton DE, Moley KH. Obesity and female infertility: potential mediators of obesity's impact. Fertil Steril. 2017;107(4):840-7. doi: 10.1016/j.fertnstert.2017.01.017.

28. Broughton DE, Moley KH. Obesity and female infertility: potential mediators of obesity's impact. Fertil Steril. 2017;107(4):840-7. doi: 10.1016/j.fertnstert.2017.01.017.

29. Ianos O, Sari-Minodier I, Villes V, Lehucher-Michel MP, Loundou A, Perrin J. Meta-analysis reveals the association between male occupational exposure to solvents and impairment of semen parameters. J Occup Environ Med. 2018;60(10):e533-42. doi: 10.1097/ JOM.0000000000001422.

30. Daoud S, Sellami A, Bouassida M, et al. Routine assessment of occupational exposure and its relation to semen quality in infertile men: a cross-sectional study. Turkish J Med Sci. 2017;47(3):902-7. doi:10.3906/sag-1605-47.

31. Penzias A, Bendikson K, Butts S, et al. Smoking and infertility: a committee opinion. Fertil Steril. 2018;110(4):611-8. doi: 10.1016/j.fertnstert.2018.06.016.

32. Caserta D, Bordi G, Segni ND, et al. The influence of cigarette smoking on a population of infertile men and women. Arch Gynecol Obstet. 2013;287:813-8.

33. Yang F, Li L, Chen JP, et al. Couple's infertility in relation to male smoking in a Chinese rural area. Asian journal of andrology. 2017;19(3):311. doi: 10.4103/1008-682X.168685.

34. Kumar S, Murarka S, Mishra VV, Gautam AK. Environmental \& lifestyle factors in deterioration of male reproductive health. Indian J Med Res. 2014 Nov;140 Suppl:S29-35.

35. Glazer $\mathrm{CH}$, Bonde JP, Eisenberg ML, et al. Male infertility and risk of nonmalignant chronic diseases: a systematic review of the epidemiological evidence. Semin Reprod Med. 2017; 35(3):282-290. doi: 10.1055/s-0037-1603568.

36. Condorelli RA, La Vignera S, Mongioì LM, Alamo A, Calogero AE. Diabetes mellitus and infertility: different pathophysiological effects in type 1 and type 2 on sperm function. Front Endocrinol (Lausanne). 2018;9:268. doi:10.3389/fendo.2018.00268

(C) 2019 The Author (s); This is an open-access article distributed under the terms of the Creative Commons Attribution License (http://creativecommons.org/licenses/by/4.0), which permits unrestricted use, distribution, and reproduction in any medium, provided the original work is properly cited. 